\title{
Gene expression profiling analysis contributes to understanding the association between non-syndromic cleft lip and palate, and cancer
}

\author{
HONGYI WANG, TAO QIU, JIE SHI, JIULONG LIANG, YANG WANG, LIANGLIANG QUAN, \\ YU ZHANG, QIAN ZHANG and KAI TAO \\ Department of Plastic Surgery, General Hospital of Shenyang Military Area Command, PLA, \\ Shenyang, Liaoning 110016, P.R. China
}

Received March 10, 2015; Accepted December 18, 2015

DOI: $10.3892 / \mathrm{mmr} .2016 .4802$

\begin{abstract}
The present study aimed to investigate the molecular mechanisms underlying non-syndromic cleft lip, with or without cleft palate (NSCL/P), and the association between this disease and cancer. The GSE42589 data set was downloaded from the Gene Expression Omnibus database, and contained seven dental pulp stem cell samples from children with NSCL/P in the exfoliation period, and six controls. Differentially expressed genes (DEGs) were screened using the RankProd method, and their potential functions were revealed by pathway enrichment analysis and construction of a pathway interaction network. Subsequently, cancer genes were obtained from six cancer databases, and the cancer-associated protein-protein interaction network for the DEGs was visualized using Cytoscape. In total, 452 upregulated and 1,288 downregulated DEGs were screened. The upregulated DEGs were significantly enriched in the arachidonic acid metabolism pathway, including $P T G D S$, $C Y P 4 F 2$ and PLA2G16; and transforming growth factor (TGF)- $\beta$ signaling pathway, including SMAD3 and TGFB2. The downregulated DEGs were distinctly involved in the pathways of DNA replication, including MCM2 and POLA1; cell cycle, including $C D K 1$ and $S T A G 1$; and viral carcinogenesis, including PIK3CA and HISTIH2BF. Furthermore, the pathways of cell cycle and viral carcinogenesis, with higher degrees of interaction were found to interact with other pathways, including DNA replication, transcriptional misregulation in cancer, and the TGF- $\beta$ signaling pathway. Additionally, TP53, $C D K 1$, SMAD3, PIK3R1 and CASP3, with higher degrees, interacted with the cancer genes. In conclusion, the DEGs
\end{abstract}

Correspondence to: Dr Kai Tao, Department of Plastic Surgery, General Hospital of Shenyang Military Area Command, PLA, 83 Wenhua Road, Shenhe, Shenyang, Liaoning 110016, P.R. China E-mail: kaitaotaoao@163.com

Key words: non-syndromic cleft lip and palate, cancer, differentially expressed genes, pathway, interaction network for NSCL/P were implicated predominantly in the TGF- $\beta$ signaling pathway, the cell cycle and in viral carcinogenesis. The TP53, CDK1, SMAD3, PIK3R1 and CASP3 genes were found to be associated, not only with NSCL/P, but also with cancer. These results may contribute to a better understanding of the molecular mechanisms of NSCL/P.

\section{Introduction}

Non-syndromic cleft lip, with or without cleft palate (NSCL/P) is one of the most common types of congenital defect and affects 3.4-22.9/10,000 individuals worldwide (1). The interaction between environmental and genetic factors during embryonic development has been identified as the determinant pathogeny of NSCL/P (2).

In previous years, common alleles affecting the susceptibility to this complex disease have been identified using genome-wide association studies $(3,4)$. However, each variant has a low incidence in NSCL/P, which introduces difficulty in determining the expected heritability for the disease (5). There is sufficient evidence that variants in interferon regulatory factor 6 (IRF6) have a substantial impact on the occurrence of NSCL/P (6). For example, a single nucleotide polymorphism (rs642961; G>A) located within an enhancer $\sim 10 \mathrm{~kb}$ upstream of the IRF6 transcription initiation site is significantly over-transmitted in NSCL/P, which can disrupt the binding site of transcription factor $A P-2 \alpha(7)$, which is a mutation in the autosomal dominant NSCL/P. In addition, mutations of MAFB, ABCA4 (8), VAX1 (9), FGFR2 (10) and SUMOI (11), as well as the perturbation of the methionine and folate pathways (12), and haplotypes in the Wnt and fibroblast growth factor signaling pathway (13) have all been confirmed to increase the risk of NSCL/P.

In addition, anomalies in cell migration, proliferation, transdifferentiation and apoptosis are considered to be closely associated to the occurrence NSCL/P $(14,15)$. These events are commonly known to be correlated with cancer. Studies have shown that alterations in certain genes, including WNT (16), MSX1 (17), BMP (18) and BCL3 (19), which are considered to be implicated in carcinogenesis, are also involved in NSCL/P (20-23). In 2013, Kobayashi et al (24) 
showed that, in NSCL/P dental pulp stem cells, BRCAI and $R A D 51$, targeted by the E2F1 transcription factor, were dysregulated in the developing embryonic orofacial primordial, and are central to lip and palate morphogenesis. In addition, cellular defences against DNA damage may be involved in determining the susceptibility to NSCL/P, which suggests an etiological overlap between this malformation and cancer (24). However, this previous study predominantly investigated differentially expressed genes (DEGs) associated with DNA double-strand break repair and cell cycle control in NSCL/P group samples, which is less convincing for the hypothesis of an etiological overlap between NSCL/P and cancer.

In the present study, the microarray data deposited by Kobayashi et al were downloaded to further reveal the interplay between the DEGs in NSCL/P samples and cancer genes, and to identify the precise nosogenesis of NSCL/P. Subsequently, pathway enrichment analysis and pathway interaction analysis of the DEGs were performed, and a cancer-associated protein-protein interaction (PPI) network for the DEGs was constructed. The results of these investigations may assist in elucidating the etiology of NSCL/P, and provide more information on the correlation between the mechanisms of NSCL/P and cancer.

\section{Materials and methods}

Affymetrix microarray data. The gene expression profile data of GSE42589 (24) were obtained from the Gene Expression Omnibus (GEO; http://www.ncbi.nlm.nih.gov/geo/), based on the GPL6244 [HuGene-1_0-st] Affymetrix Human Gene 1.0 ST Array platform (Affymetrix, Santa Clara, CA, USA; http://www.ncbi.nlm.nih.gov/geo/query/acc. cgi?acc=GPL6244). In total, 13 dental pulp stem cell samples were available for further analysis, including seven dental pulp stem cell samples collected from children with NSCL/P in the exfoliation period, and six controls obtained from healthy children in the exfoliation period. This study was approved by the Biosciences Institute Research Ethics Committee (Protocol 037/2005) at the University of São Paulo (São Paulo, Brazil), and all the patients or legal guardians signed informed-consent documents (22). All samples were cultured in Dulbecco's modified Eagle's medium/Ham's F-12 medium (Life Technologies; Thermo Fisher Scientific, Inc., Waltham, MA, USA) supplemented with $15 \%$ fetal bovine serum (HyClone, Logan, UT, USA), $1 \%$ non-essential amino acids solution (Life Technologies; Thermo Fisher Scientific, Inc.) and $1 \%$ penicillin-streptomycin solution (Life Technologies; Thermo Fisher Scientific, Inc.), in a humidified incubator at $37^{\circ} \mathrm{C}$ and $5 \% \mathrm{CO}_{2}$.

CEL files and the probe annotation files were downloaded, and the gene expression data of all samples were normalized using the Robust Multi-array Average (25) algorithm of the Bioconductor Affy package in R (http://www.bioconductor. org/packages/release/bioc/html/affy.html) (26).

Screening of DEGs. The RankProd method (27) in the Bioconductor package was used to identify genes, which were significantly differentially expressed in the NSCL/P dental pulp stem cells. The raw P-value was adjusted into the false discovery rate (FDR) using the Benjamin and Hochberg method (28), and only the genes within the cut-off criteria of $\| \log _{2}$ fold changel $>1$ and FDR $<0.05$ were selected as DEGs.

Pathway enrichment analysis. To identify the significant metabolic pathways for the DEGs, the screened DEGs were submitted to the Kyoto Encyclopedia of Genes and Genomes (KEGG) database (http://www.genome.jp/kegg/kegg1.html) for pathway enrichment analysis (29). An FDR $<0.1$ was used as the cut-off criterion.

Pathway interaction analysis. Pathway interactions were analyzed based on the association between the DEGs in the pathways, which was determined from the protein-protein interaction (PPI) network for the DEGs, obtained from the human protein reference database (http://www.hprd.org/) (30). The pathway interaction network was visualized using Cytoscape (http://cytoscape.org/) (31).

Construction of the cancer-associated PPI network. Cancer genes were obtained from the a database of Functional Census of Human Cancer Genes (http://210.46.85.180:8080/ fcensus/) (32), which provides multiple dimension information for cancer genes, including cancer type, cancer gene type, mutation type and mutation frequency, calculated from high-throughput mutational screens of cancer genomes. The $\mathrm{R}$ package was used to obtain the interactions between the DEGs and cancer genes. The five DEGs exhibiting the highest degree were selected to construct the PPI network, and the network was visualized using Cytoscape.

\section{Results}

Identification of DEGs. Based on the cut-off criteria used for determination of the DEGs, a total of 1,740 DEGs were identified in the NSCL/P samples, including 452 upregulated DEGs and 1,288 downregulated DEGs.

Pathway enrichment analysis of the upregulated and downregulated DEGs. The upregulated DEGs were significantly enriched in three pathways: Seven DEGs, including TGFB2, $T G F B 3$ and $V C A M 1$, were enriched in the hsa05144 malaria pathway (FDR=6.27E-02); seven DEGs, including PTGDS, PTGIS, CYP4F2, PTGES and PLA2G16 were enriched in the hsa00590 arachidonic acid metabolism pathway (FDR=9.75E-02); and eight DEGs, including ID2, ID4, $S M A D 3$ and TGFB2, were involved in the hsa04350 TGF- $\beta$ signaling pathway (FDR=9.75E-02; Table I).

The downregulated DEGs were significantly enriched in 17 pathways. DEGs, including MCM2, MCM4, PRIM1, POLA1 and POLA2 were enriched in the pathway of hsa03030 DNA replication (FDR=7.58E-10); DEGs, including UTP6, GTPBP4 and GNL3 were correlated with hsa03008 ribosome biogenesis in eukaryotes (FDR=9.07E-06); DEGs including RAD51 and TOP $3 A$, were associated with hsa03440 homologous recombination (FDR=1.78E-05); DEGs, including CDC6, MCM2, CDK1, STAG1 and ANAPC10, were implicated in hsa04110 cell cycle (FDR=1.75E-04); DEGs, including PIK3RI, CASP3, HIST1H2BL and HISTIH2BF, were enriched in the hsa05203 viral carcinogenesis pathway 


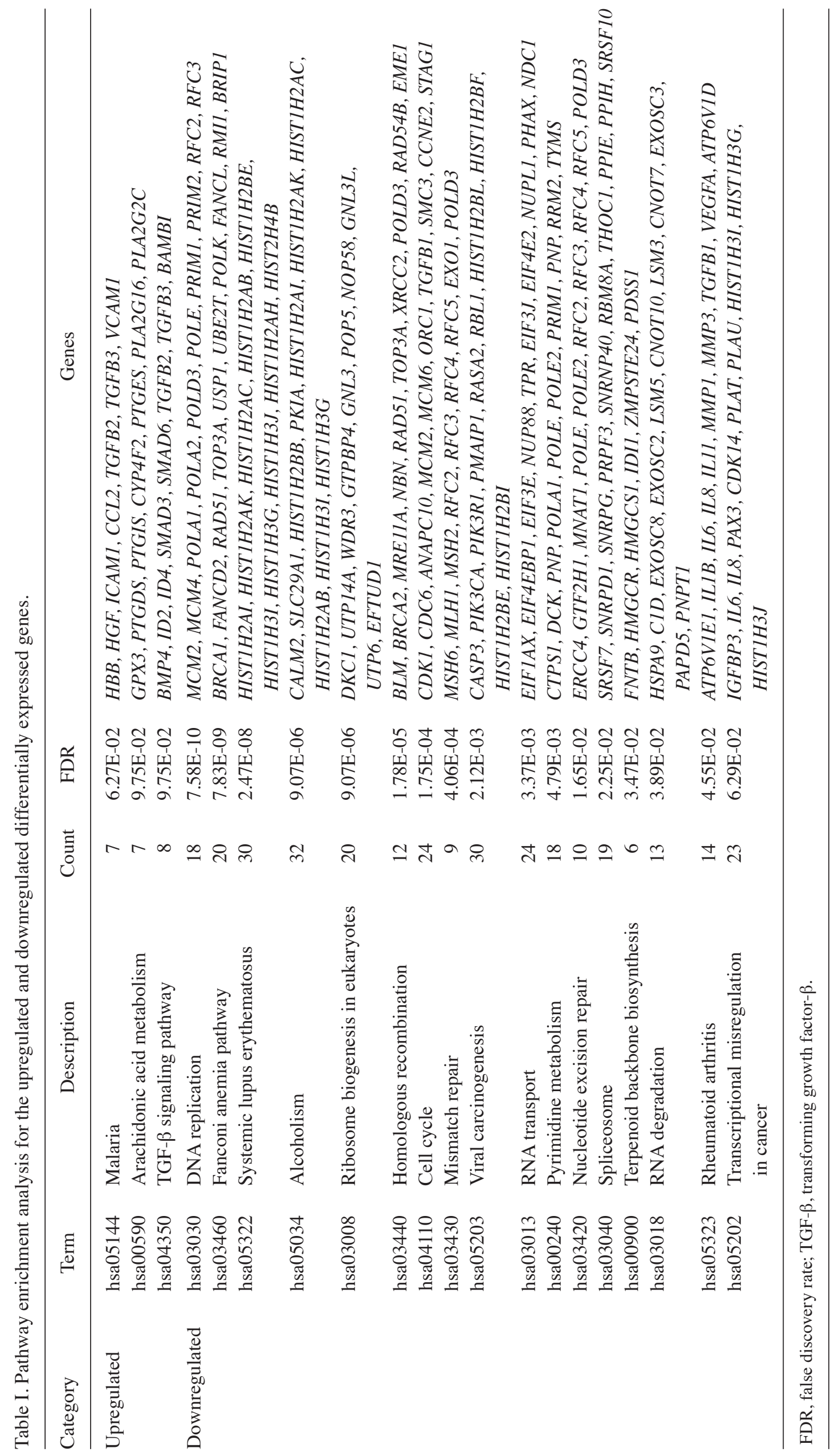




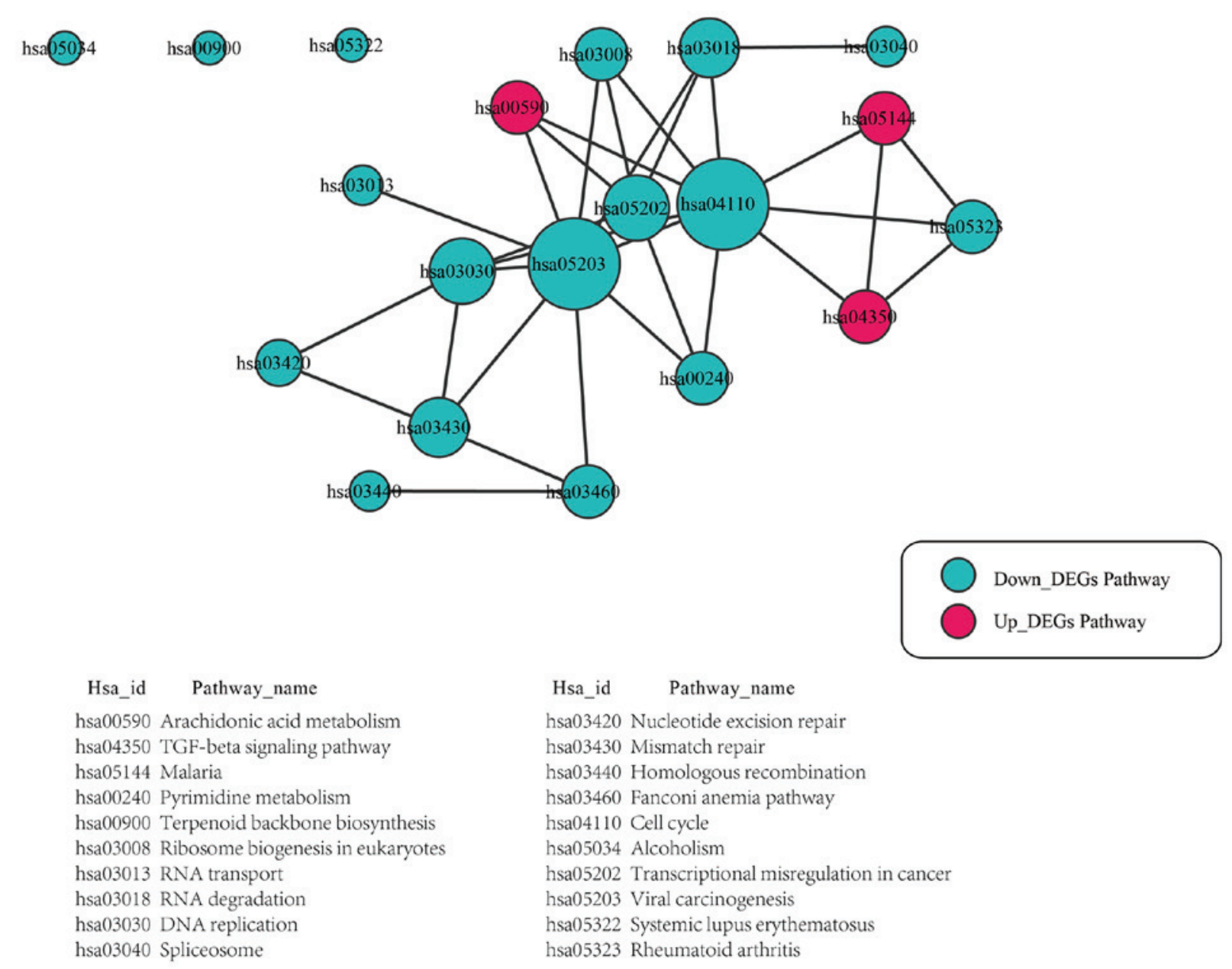

Figure 1. Pathway interaction network for the upregulated and downregulated DEGs. The size of the nodes indicates the number of pathway interactions. DEGs, differentially expressed genes; TGF- $\beta$, transforming growth factor- $\beta$.

$($ FDR=2.12E-03); and DEGs, including POLA1, PNP and $P R I M 1$, were implicated in hsa00240 pyrimidine metabolism $(\mathrm{FDR}=4.79 \mathrm{E}-03$; Table I).

Pathway interaction analysis. In the pathway interaction network, the pathways of the hsa04110 cell cycle and hsa05203 viral carcinogenesis had the highest degrees of interaction, and interacted with other pathways, including hsa03030 DNA replication, hsa03008 ribosome biogenesis in eukaryotes, hsa00590 arachidonic acid metabolism, hsa00240 pyrimidine metabolism, and hsa03018 RNA degradation. In addition, the hsa04110 cell cycle pathway was found to interacted with the pathways of hsa05203 viral carcinogenesis and hsa04350 TGF- $\beta$ signaling pathway (Fig. 1).

Analysis of the cancer-associated PPI network. In total, 2,617 interaction pairs of DEGs and cancer genes were screened in the present study. The five DEGs with the highest degree were TP53, SMAD3, PIK3R1, CASP3 and CDK1, and their degrees were 104, 75, 67, 60 and 54, respectively.

With the exception of $C A S P 3$, the four residual genes (TP53, SMAD3, PIK3R1 and CDK1) were not only DEGs of NSCL/P, but were also identified as cancer genes. In the PPI network, TP53 was directly associated with E2F1, GNL3, PRIM1, PNP and POLA1; CDK1 was associated with E2F1, MCM4 and
POLA1; CASP3 was directly associated with $M L H 1, B L M$, BRCA1 and RAD51, as well as TP53 and PIK3R1.SMAD3, and $T P 53$, were associated to certain cancer genes, including $T P 73$, IL16, MAPK1, MAPK9 and CDK2; and SMAD3 was found to interact with $A N A P C 10$ (Fig. 2).

\section{Discussion}

In the present study, 452 DEGs were identified to be significantly upregulated and 1,288 were found to be downregulated in the NSCL/P samples. According to the analysis of the cancer-associated PPI network, the five DEGs with the highest degrees were TP53, SMAD3, PIK3R1, CASP3 and CDK1. Among these, TP53, SMAD3, PIK3R1 and CDK1 were not only DEGs for NSCL/P, but were also associated with cancer.

$T P 53$, encoding the 53 protein, acts as a tumor suppressor, and its loss of function is a precondition for almost all types of cancer (33). The effector functions of p53 range from arresting the cell cycle to inducing more substantial events, including senescence or apoptosis (34). A previous study demonstrated that the transcription factor p63, a homologue of p53, can transactivate IRF6 by binding to an upstream enhancer element, whose genetic variation is associated with increased susceptibility to cleft lip (35). It is also possible that p63 may be an important upstream regulator of desmosomal cell 


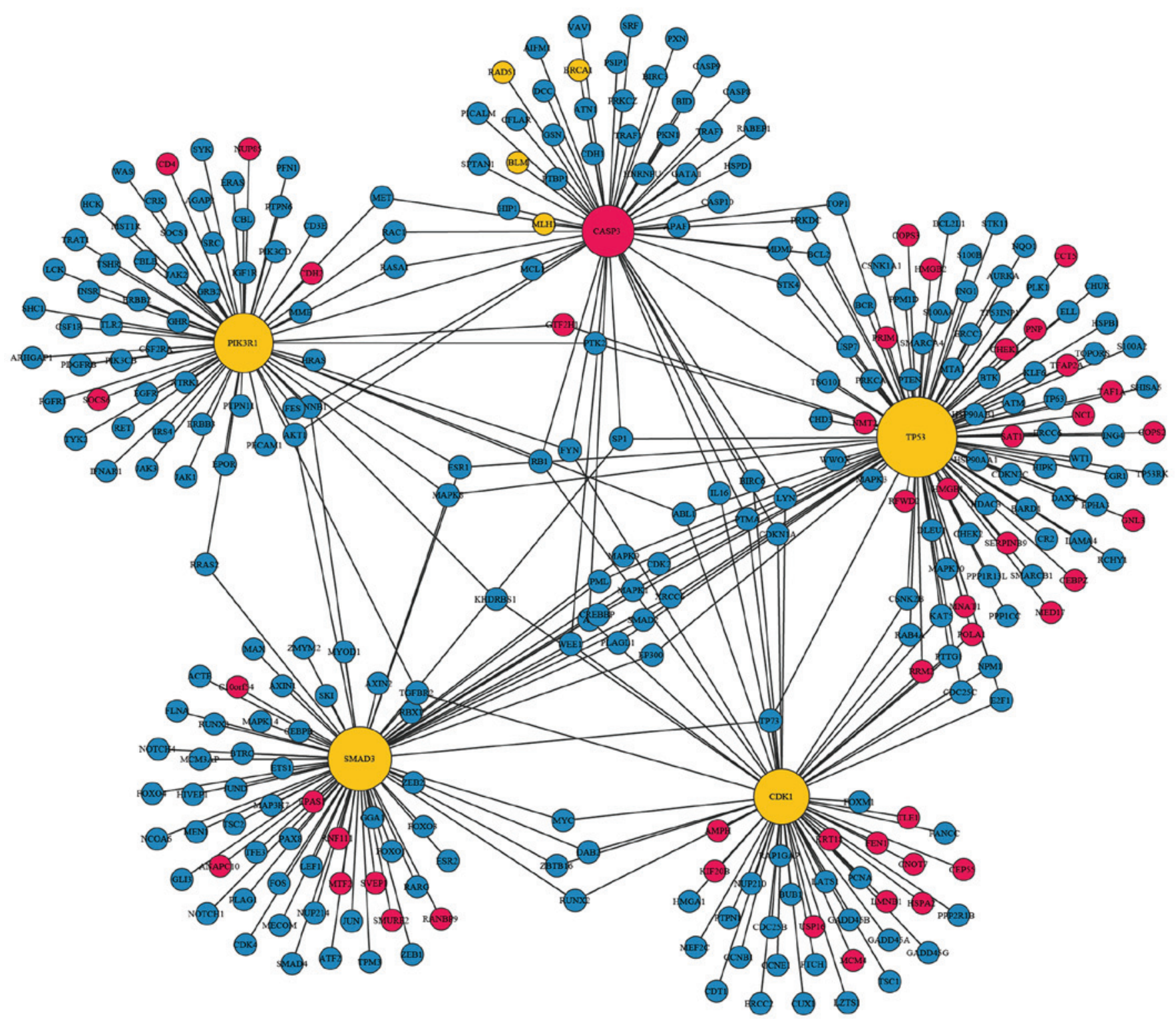

Figure 2. Cancer-associated PPI network for the five DEGs with the highest degree. Yellow nodes represent the DEGs in both NSCL/P and cancer; red nodes represent the DEGs only in NSCL/P; blue nodes represent the cancer genes. The size of the nodes indicate the degree of interaction of the DEGs; PPI, protein-protein interaction; DEGs, differentially expressed genes; NSCL/P, non-syndromic cleft lip, with or without cleft palate.

adhesion, which may contribute to the skin fragility observed in patients with cleft lip and palate (36). In addition, the L514F mutation in the sterile $\alpha$-motif region of p63 can interrupt the binding of p63 to the RNA-processing protein, ABBP1, which leads to aberrant splicing of the keratinocyte growth factor receptor and inhibition of epithelial differentiation (37). The present study observed that TP53 was directly associated with GNL3, PRIM1, PNP and POLA1. GNL3, encoding guanine nucleotide binding protein-like 3 , was enriched in the pathway of ribosome biogenesis in eukaryotes; PRIMI, encoding polypeptide 1 of DNA primase; $P N P$, encoding purine nucleoside phosphorylase; and POLAl, encoding the catalytic subunit of DNA polymerase, were enriched in the pathway of pyrimidine metabolism. PRIMI and POLAl were also associated with DNA replication. These pathways were all involved in the process of cell proliferation Normal palate and orofacial morphogenesis requires mesenchymal cell proliferation and differentiation, and inhibiting the progression of cell cycle between the G1 and S phases in human embryonic palatal mesenchymal cells may induce cleft palate (38). Thus, TP53 may be key in NSCL/P by modulating ribosome biogenesis, pyrimidine metabolism and DNA replication via interactions with GNL3, PRIMI, PNP and POLA1.

In addition, $C D K 1$ was found to interact with POLAl, as well as MCM4, which were enriched in DNA replication. $C D K 1$ encodes cyclin-dependent kinase 1 , a catalytic subunit of M-phase promoting factor, which is crucial for G1/S and G2/M phase transitions in eukaryotic cell cycle (39). In addition, $C D K 1$ and TP53 were observed to be associated with $E 2 F 1$. E2F1, a master regulator of cell cycle, can promote the $\mathrm{G} 1 / \mathrm{S}$ transition, transactivating a variety of genes involved in chromosomal DNA replication, including its own promoter (40). Increased $E 2 F 1$ activity can promote tumorigenesis (41). A previous study reported that $E 2 F 1$ may be involved during murine palatogenesis (42). The present study also observed that the pathway of the cell cycle interacted with 
the pathway of viral carcinogenesis, and PIK3RI and CASP3 were enriched in viral carcinogenesis. $P I K 3 R 1$, encoding the $\mathrm{p} 85 \alpha$ regulatory subunit of phosphoinositide-3-kinase is known to be associated with a series of cellular processes associated with malignant behavior, including proliferation, adherence, transformation and survival (43). A PIK3Rl mutant has been identified in glioblastoma, ovarian cancer and colon cancer $(44,45)$. In addition, $C A S P 3$, encoding a member of the cysteine-aspartic acid protease (caspase) family, is important in the extrinsic and intrinsic apoptotic pathways (46). A previous study suggested that increased expression of CASP3 is associated with tumors of the mouth (47). Thereby, $C D K 1$, together with POLA1, MCM4, E2F1, PIK3R1 and CASP3 may not only be critical in the development of NSCL/P, but also in cancer.

$S M A D 3$, a member of the $S M A D$ family, was enriched in the TGF- $\beta$ signaling pathway. SMAD family members are essential intracellular signaling components of the TGF- $\beta$ superfamily (48). TGF- $\beta$ is a cytokine, which controls the proliferation, differentiation, migration and apoptosis of several different cell types, and is important in mediating epithelial-mesenchymal transformation during the normal fusion of the lip and palate $(49,50)$. It has been confirmed that TGF- $\beta 3$ can promote fetal cleft lip repair and fusion in mouse fetuses by increasing the availability of mesenchymal cells or inducing expression of cyclin D1 (49). Also, TGF- $\beta$ can promote tumor cell proliferation by stimulating the production of autocrine mitogenic factors, such as platelet-derived growth factor B (51). TGF- $\beta$ can contribute to tumor invasion by inducing eithelial-mesenchymal transition (52). TGF- $\beta$ can also enhance cell motility by cooperating with $E R B B 2$, which is observed to be overexpressed in breast cancer cells (53). In addition, TGF- $\beta$ can suppress immunity in patients with human glioma via decreasing the expression of the activating immunoreceptor, NKG2D, in CD8+ T cells and natural killer cells, and repressing the expression of the NKG2D ligand, MICA (54). In the present study, SMAD3 was found to interact with ANAPC10, which was enriched in the pathway of cell cycle. Thereby, SMAD3 may be an important gene in the development of NSCL/P and cancer.

In conclusion, 452 upregulated and 1,288 downregulated DEGs were identified in the present study. Five important DEGs, including TP53, CDK1 and SMAD3, may be associated with both NSCL/P and cancer. These results suggested correlation between the pathogenesis of NSCL/P and cancer, which may provide novel information for the clinical diagnosis of NSCL/P.

\section{References}

1. Mossey PA, Little J, Munger RG, Dixon MJ and Shaw WC: Cleft lip and palate. Lancet 374: 1773-1785, 2009.

2. Dixon MJ, Marazita ML, Beaty TH and Murray JC: Cleft lip and palate: Understanding genetic and environmental influences. Nat Rev Genet 12: 167-178, 2011.

3. Birnbaum S, Ludwig KU, Reutter H, Herms S, Steffens M, Rubini M, Baluardo C, Ferrian M, Almeida de Assis N, Alblas MA, et al: Key susceptibility locus for nonsyndromic cleft lip with or without cleft palate on chromosome 8q24. Nat Genet 41: 473-477, 2009.

4. Grant SF, Wang K, Zhang H, Glaberson W, Annaiah K, Kim CE, Bradfield JP, Glessner JT, Thomas KA, Garris M, et al: A genomewide association study identifies a locus for nonsyndromic cleft lip with or without cleft palate on 8q24. J Pediatr 155: 909-913, 2009.
5. Maher B: Personal genomes: The case of the missing heritability. Nature 456: 18-21, 2008.

6. Roessler E, Belloni E, Gaudenz K, Jay P, Berta P, Scherer SW, Tsui LC and Muenke M: Mutations in the human Sonic Hedgehog gene cause holoprosencephaly. Nat Genet 14: 357-360, 1996.

7. Rahimov F, Marazita ML, Visel A, Cooper ME, Hitchler MJ, Rubini M, Domann FE, Govil M, Christensen K, Bille C, et al: Disruption of an AP-2alpha binding site in an IRF6 enhancer is associated with cleft lip. Nat Genet 40: 1341-1347, 2008.

8. Beaty TH, Murray JC, Marazita ML, Munger RG, Ruczinski I, Hetmanski JB, Liang KY, Wu T, Murray T, Fallin MD, et al: A genome-wide association study of cleft lip with and without cleft palate identifies risk variants near MAFB and ABCA4. Nat Genet 42: 525-529, 2010.

9. Mangold E, Ludwig KU, Birnbaum S, Baluardo C, Ferrian M, Herms S, Reutter H, de Assis NA, Chawa TA, Mattheisen M, et al: Genome-wide association study identifies two susceptibility loci for nonsyndromic cleft lip with or without cleft palate. Nat Genet 42: 24-26, 2010.

10. Osoegawa K, Vessere GM, Utami KH, Mansilla MA, Johnson MK, Riley BM, L'Heureux J, Pfundt R, Staaf J, van der Vliet WA, et al: Identification of novel candidate genes associated with cleft lip and palate using array comparative genomic hybridization. J Med Genet 45: 81-86, 2008.

11. Mostowska A, Hozyasz KK, Wojcicki P, Biedziak B, Paradowska P and Jagodzinski PP: Association between genetic variants of reported candidate genes or regions and risk of cleft lip with or without cleft palate in the polish population. Birth Deffects Res A Clin Mol Teratol 88: 538-545, 2010.

12. Blanton SH, Henry RR, Yuan Q, Mulliken JB, Stal S, Finnell RH and Hecht JT: Folate pathway and nonsyndromic cleft lip and palate. Birth Deffects Res A Clin Mol Teratol 91: 50-60, 2011.

13. Nikopensius T, Jagomägi T, Krjutškov K, Tammekivi V, Saag M, Prane I, Piekuse L, Akota I, Barkane B, Krumina A, et al: Genetic variants in COL2A1, COL11A2 and IRF6 contribute risk to nonsyndromic cleft palate. Birth Deffects Res A Clin Mol Teratol 88: 748-756, 2010.

14. Greene RM and Pisano MM: Palate morphogenesis: Current understanding and future directions. Birth Defects Res C Embryo Today 90: 133-154, 2010.

15. Yu W, Serrano M, Miguel SS, Ruest LB and Svoboda KK: Cleft lip and palate genetics and application in early embryological development. Indian J Plast Surg 42 (Suppl): S35-S50, 2009.

16. Wend P, Holland JD, Ziebold U and Birchmeier W: Wnt signaling in stem and cancer stem cells. Semin Cell Dev Biol 21: 855-863, 2010.

17. Park K, Kim K, Rho SB, Choi K, Kim D, Oh SH, Park J, Lee SH and Lee JH: Homeobox Msx1 interacts with p53 tumor suppressor and inhibits tumor growth by inducing apoptosis. Cancer Res 65: 749-757, 2005.

18. Sagorny K, Chapellier M, Laperrousaz B and Maguer-Satta V: BMP and cancer: The Yin and Yang of stem cells. Med Sci (Paris) 28: 416-422, 2012 (In French).

19. Guan Y, Yao H, Zheng Z, Qiu G and Sun K: MiR-125b targets BCL3 and suppresses ovarian cancer proliferation. Int J Cancer 128: 2274-2283, 2011.

20. Chiquet BT, Blanton SH, Burt A, Ma D, Stal S, Mulliken JB and Hecht JT: Variation in WNT genes is associated with non-syndromic cleft lip with or without cleft palate. Hum Mol Genet 17: 2212-2218, 2008.

21. Cardoso ML, Bezerra JF, Oliveira GH, Soares CD, Oliveira SR, de Souza KS, da Silva HP, Silbiger VN, Luchessi AD, Fajardo CM, et al: MSX1 gene polymorphisms in non-syndromic cleft lip and/or palate. Oral Dis 19: 507-512, 2013.

22. Mostowska A, Hozyasz KK, Wojcicka K, Biedziak B and Jagodzinski PP: Polymorphic variants at 10q25.3 and 17q22 loci and the risk of non-syndromic cleft lip and palate in the polish population. Birth Deffects Res A Clin Mol Teratol 94: 42-46, 2012.

23. Jagomägi T, Nikopensius T, Krjutškov K, Tammekivi V, Viltrop T, Saag M and Metspalu A: MTHFR and MSX1 contribute to the risk of nonsyndromic cleft lip/palate. Eur J Oral Sci 118: 213-220, 2010.

24. Kobayashi GS, Alvizi L, Sunaga DY, Francis-West P, Kuta A, Almada BV, Ferreira SG, de Andrade-Lima LC, Bueno DF, Raposo-Amaral CE, et al: Susceptibility to DNA damage as a molecular mechanism for non-syndromic cleft lip and palate. PLoS One 8: e65677, 2013. 
25. Irizarry RA, Hobbs B, Collin F, Beazer-Barclay YD, Antonellis KJ, Scherf U and Speed TP: Exploration, normalization and summaries of high density oligonucleotide array probe level data. Biostatistics 4: 249-264, 2003.

26. Wilson CL and Miller CJ: Simpleaffy: A BioConductor package for affymetrix quality control and data analysis. Bioinformatics 21: 3683-3685, 2005.

27. Hong F, Breitling R, McEntee CW, Wittner BS, Nemhauser JL and Chory J: RankProd: A bioconductor package for detecting differentially expressed genes in meta-analysis. Bioinformatics 22 : 2825-2827, 2006.

28. Benjamini Y and Hochberg Y: Controlling the false discovery rate: A practical and powerful approach to multiple testing. J Roy Stat Soc B 57: 289-300, 1995.

29. Huang DW, Sherman BT and Lempicki RA: Bioinformatics enrichment tools: Paths toward the comprehensive functional analysis of large gene lists. Nucleic Acids Res 37: 1-13, 2009.

30. Baolin L and Bo H: HPRD: A high performance RDF database. In: Network and Parallel Computing. Li K, Jesshope C, Jin $\mathrm{H}$ and Gaudiot JL (Eds). Vol 4672. Springer Berlin Heidelberg, Germany, pp364-374, 2007.

31. Kohl M, Wiese S and Warscheid B: Cytoscape: Software for visualization and analysis of biological networks. Methods $\mathrm{Mol}$ Biol 696: 291-303, 2011

32. Gong X, Wu R, Zhang Y, Zhao W, Cheng L, Gu Y, Zhang L, Wang J, Zhu J and Guo Z: Extracting consistent knowledge from highly inconsistent cancer gene data sources. BMC Bioinformatics 11: 76, 2010.

33. van Bokhoven $\mathrm{H}$ and McKeon F: Mutations in the p53 homolog p63: Allele-specific developmental syndromes in humans. Trends Mol Med 8: 133-139, 2002.

34. Malkin D, Li FP, Strong LC, Fraumeni JF Jr, Nelson CE, Kim DH, Kassel J, Gryka MA, Bischoff FZ and Tainsky MA: Germ line p53 mutations in a familial syndrome of breast cancer, sarcomas and other neoplasms. Science 250: 1233-1238, 1990

35. Thomason HA, Zhou H, Kouwenhoven EN, Dotto GP, Restivo G, Nguyen BC, Little H, Dixon MJ, van Bokhoven H and Dixon J: Cooperation between the transcription factors p63 and IRF6 is essential to prevent cleft palate in mice. J Clin Invest 120 : $1561-1569,2010$

36. McGrath JA, Hoeger PH, Christiano AM, McMillan JR, Mellerio JE, Ashton GH, Dopping-Hepenstal PJ, Lake BD, Leigh IM, Harper JI and Eady RA: Skin fragility and hypohidrotic ectodermal dysplasia resulting from ablation of plakophilin 1. Brit J Dermatol 140: 297-307, 1999.

37. Fomenkov A, Huang YP, Topaloglu O, Brechman A, Osada M Fomenkova T, Yuriditsky E, Trink B, Sidransky D and Ratovitski E: P63 alpha mutations lead to aberrant splicing of keratinocyte growth factor receptor in the Hay-Wells syndrome. J Biol Chem 278: 23906-23914, 2003.

38. Dhulipala VC, Welshons WV and Reddy CS: Inhibition of human embryonic palatal mesenchymal cell cycle by secalonic acid D: A probable mechanism of its cleft palate induction. Orthod Craniofac Res 7: 227-236, 2004.

39. Ekholm SV and Reed SI: Regulation of G(1) cyclin-dependent kinases in the mammalian cell cycle. Curr Opin Cell Biol 12: 676-684, 2000.

40. DeGregori J: The genetics of the E2F family of transcription factors: Shared functions and unique roles. Biochim Biophys Acta 1602: 131-150, 2002.
41. Pierce AM, Schneider-Broussard R, Gimenez-Conti IB, Russell JL, Conti CJ and Johnson DG: E2F1 has both oncogenic and tumor-suppressive properties in a transgenic model. Mol Cell Biol 19: 6408-6414, 1999.

42. Kusek JC, Greene RM, Nugent $P$ and Pisano M: Expression of the E2F family of transcription factors during murine development. Int J Dev Biol 44: 267-278, 2000.

43. Roymans D and Slegers H: Phosphatidylinositol 3-kinases in tumor progression. Eur J Biochem 268: 487-498, 2001

44. Philp AJ, Campbell IG, Leet C, Vincan E, Rockman SP, Whitehead RH, Thomas RJ and Phillips WA: The phosphatidylinositol 3'-kinase p85alpha gene is an oncogene in human ovarian and colon tumors. Cancer Res 61: 7426-7429, 2001.

45. Mizoguchi M, Nutt CL, Mohapatra G and Louis DN: Genetic alterations of Phosphoinositide 3-kinase subunit genes in human glioblastomas. Brain Pathol 14: 372-377, 2004.

46. Calogero AE, Soma PF, Giuffrida MC, Giuffrida D, La Vignera S, Romano C, Castiglione R, Bosco P and Salemi M: PARP1 and CASP3 gene expression in a patient with multiple head and neck squamous cell carcinoma and Parkinson disease. Hum Cell 26: 44-46, 2013.

47. Coutinho-Camillo CM, Lourenço SV, Nishimoto IN, Kowalski LP and Soares FA: Caspase expression in oral squamous cell carcinoma. Head Neck 33:1191-1198, 2011.

48. Nakao A, Imamura T, Souchelnytskyi S, Kawabata M, Ishisaki A, Oeda E, Tamaki K, Hanai J, Heldin CH, Miyazono K and ten Dijke P: TGF-beta receptor-mediated signalling through Smad2, Smad3 and Smad4. EMBO J 16: 5353-5362, 1997.

49. Kohama K, Nonaka K, Hosokawa R, Shum L and Ohishi M: TGF-beta-3 promotes scarless repair of cleft lip in mouse fetuses. J Dent Res 81: 688-694, 2002.

50. Roberts AB and Sporn MB: Physiological actions and clinical applications of transforming growth factor-beta (TGF-beta). Growth factors 8: 1-9, 1993.

51. Bruna A, Darken RS, Rojo F, Ocaña A, Peñuelas S, Arias A, Paris R, Tortosa A, Mora J, Baselga J and Seoane J: High TGFbeta-Smad activity confers poor prognosis in glioma patients and promotes cell proliferation depending on the methylation of the PDGF-B gene. Cancer Cell 11: 147-160, 2007.

52. Mani SA, Guo W, Liao MJ, Eaton EN, Ayyanan A, Zhou AY, Brooks M, Reinhard F, Zhang CC, Shipitsin M, et al: The epithelial-mesenchymal transition generates cells with properties of stem cells. Cell 133: 704-715, 2008

53. Seton-Rogers SE, Lu Y, Hines LM, Koundinya M, LaBaer J, Muthuswamy SK and Brugge JS: Cooperation of the ErbB2 receptor and transforming growth factor beta in induction of migration and invasion in mammary epithelial cells. Proc Natl Acad Sci USA 101: 1257-1262, 2004.

54. Friese MA, Wischhusen J, Wick W, Weiler M, Eisele G, Steinle A and Weller M: RNA interference targeting transforming growth factor-beta enhances NKG2D-mediated antiglioma immune response, inhibits glioma cell migration and invasiveness and abrogates tumorigenicity in vivo. Cancer Res 64: 7596-7603, 2004 . 